\title{
La medicina y cirugía experimental, entre la apocatástasis y la manotecnología
}

La Sanidad Militar, no se nos escapa a ninguno, se está preparando para una profunda remodelación. Un nuevo modelo se avecina. Esta es la razón del título de esta editorial. He utilizado deliberadamente estos extraños y llamativos términos con el único objeto de atraer inmediatamente la atención del lector hacia un asunto que nos va a permitir mejorar la formación e instrucción de nuestros cirujanos dentro de ese nuevo modelo que perseguimos. La cirugía del tiempo presente es una disciplina científica capaz de obtener los más asombrosos resultados. Precisamente ha sido el desarrollo tecnológico el que ha permitido avances trascendentales en el campo de la cirugía, al menos desde las últimas décadas del siglo XX. Principalmente la cirugía mínimamente invasiva (laparoscopia) ha logrado disminuir los tiempos de recuperación y las complicaciones postquirúrgicas en muchas intervenciones. La telemedicina o la robótica han dotado también de nuevas herramientas a los cirujanos, permitiendo el desarrollo de intervenciones a distancia, o con un nivel de precisión muy superior al del ojo humano. Por otra parte, la aparición de nuevas técnicas de detección de imagen como las de Ecografía de última generación, Endoscopia, RMN o PET entre otras, ha posibilitado el desarrollo de intervenciones selectivas mucho menos agresivas y más seguras.

De este modo comprobamos que la medicina es uno de los sectores que está siendo profundamente influido por los nuevos materiales desarrollados por la ingeniería y, como consecuencia de ello, por la aparición de dispositivos nanoescalares. La nanotecnología o el diseño de sistemas quirúrgicos automatizados son los avances que transformarán el modo de desarrollar esta disciplina médica a la que podemos denominar como «medicina nanológica».

Pero qué sucede con el otro término de tan extraña, pedante y difícil pronunciación que he utilizado para fijar su atención. La «apocatástasis» es un término filosófico que significa: «Retorno de todas las cosas o de cualquiera de ellas a su primitivo punto de partida» o bien «restituir, reintegrar, devolver a su estado primitivo las cosas». En realidad hace alusión a la recuperación del orden inicial, e incluso, arrimando el ascua a nuestro asunto, se puede hablar de regeneración o «nueva creación». Por todo ello los nuevos cirujanos de las Fuerzas Armadas requerirán también de un nuevo modelo de instrucción y de perfeccionamiento de sus técnicas.

Ahora, más que nunca, los servicios de medicina y cirugía experimental están llamados a recorrer un nuevo camino, una «apocatástasis». Para ello se requiere un cambio de mentalidad de sus responsables y de las personas llamadas a utilizarlos.

Precisamente nuestra estructura sanitaria dispone de un excelente servicio de medicina y cirugía experimental que está siendo remodelado para subvenir a las necesidades de una nueva medicina militar. Se ha mejorado notablemente el servicio de radiología, dotándolo de un sistema de radiología digital, de un nuevo ecógrafo, de un microscopio para cirugía oftalmológica y, recientemente, se le ha incorporado cuatro simuladores para la práctica de la cirugía de mínima invasión. También se han realizado las obras oportunas para incorporar un microscopio electrónico que permitirá a los investigadores completar sus estudios. Aún con ser mucho lo alcanzado con todas las mejoras introducidas no nos sentimos satisfechos y ya están sentadas las bases para incorporar una nueva columna de quirófano destinada a la cirugía traumatológica, un resonador y también nuevos modelos inanimados para la mejora de las técnicas de microcirugía, aspectos todos ellos que conviene atender con generosidad y prontitud. Para ello es necesario disponer de los modelos biológicos apropiados.

Contar con un bioterio en funcionamiento no es fácil. Supone un esfuerzo añadido en personal cualificado. Nuestro bioterio cubre las necesidades actuales de instrucción e investigación y además está atendido por personal idóneo, y nuestra intención es reforzarlo en los próximos meses.

Como es fácil comprender la utilidad de este servicio estriba en su capacidad de atender la formación, la instrucción y la investigación del personal facultativo. En la medida que lo cumpla este servicio está llamado a participar directamente en la «enseñanza de formación» de los alumnos de nuevo ingreso en el Cuerpo Militar de Sanidad y por extensión también en la «enseñanza de perfeccionamiento» de las diferentes especialidades del Cuerpo Militar de Sanidad.

Sus acciones se concretarán en:

- Instruir a los alumnos de nuevo ingreso, futuros miembros del Cuerpo Militar de Sanidad.

- Formar a los alumnos que cursan especialidades quirúrgicas de medicina, veterinaria, odontología y de enfermería.

- Impartir cursos de formación e instrucción continuada en diferentes áreas de interés, como técnicas básicas de cirugía, venopunciones, microcirugía, introducción y entrenamiento de cirugía de mínima invasión, soporte vital avanzado, cirugía urológica y otras técnicas que ya se están preparando sobre modelos inertes, in vitro y biológicos.

- Organizar seminarios y sesiones de cirugía artroscópica virtual.

- Preparar sesiones para estimular la investigación.

- Redactar un manual de procedimientos de experimentación para nuestros sanitarios, y

- Formar parte del comité de ética y bienestar animal para el cumplimiento de la legislación vigente.

Y todo ello sin desdeñar que es el sitio idóneo para la realización de tesinas y tesis doctorales de todas las especialidades fundamentales. Este servicio, con un poco de paciencia y generosidad, está llamado a ser en poco tiempo un espacio de acogida y reunión de los amantes de la Ciencia. Verdaderamente entre la «apocatástasis» como ente regenerador, y la «nanotecnología», como camino de futuro, aparecen los servicios de medicina y cirugía experimental, iy nosotros tenemos uno!

Luis Ángel Moreno Fernández-Caparrós General de Brigada Veterinario Académico 